\title{
ACESSO À JUSTIÇA EM TEMPOS DE PANDEMIA DE COVID19: UMA SOLUÇÃO CONSENSUAL E TECNOLÓGICA PARA OS CONFLITOS TRABALHISTAS
}

\section{ACCESS TO JUSTICE IN TIMES OF COVID19 PANDEMIC: A CONSENSUS AND TECHNOLOGICAL SOLUTION FOR LABOR CONFLICTS}

\author{
Marcela Casanova Viana Arena ${ }^{1}$ \\ Ana Cristina dos Santos Porto ${ }^{2}$ \\ Denice Machado de Campos ${ }^{3}$
}

Resumo: Este trabalho tem como objetivo estudar os métodos adequados de solução de conflitos trabalhistas, aliados à via tecnológica, em tempos de pandemia de Covid19, como forma de acesso à justiça. A contribuição científica da pesquisa consiste na possibilidade de conjugação dos métodos adequados e tecnologia como forma de acesso à justiça, abordando os diferentes formatos para a consensualidade adotados na seara laboral, em consonância com o sistema multiportas de resolução de conflitos. O consensualismo e a pacificação social são a justificativa principal deste estudo. Para tanto, a pesquisa utilizará o método de abordagem dedutivo, aliado à técnica de pesquisa bibliográfica e documental.

Palavras-chave: Acesso à Justiça; Sistema Multiportas; Conflitos Trabalhistas; Tecnologia; Covid19

Abstract: This word is aims study appropriate methods of solving labor conflicts, combined with the technological alternative, in times of covid19 pandemic, was a way of access to justice. The scientific contribution of the research consists of the possibility of combining the appropriate methods and technology was a way of accessing justice, addressing the diferente formats for consensus adopted in the labor law, in line the multidoor conflict resoltuion system. Consensualism and social pacification are the main justification of the study. For this, the research will use the deductive approach method, combined of the technique of bibliographic and documentary research.

Key Words: Access to Justice; Multi-door System; Labor Conflicts; Technology; Covid19

\section{INTRODUÇÃO}

\footnotetext{
${ }^{1}$ Mestranda em Direitos Sociais no Programa de Pós-Graduação em Direito da Universidade Federal de Pelotas. Juíza do Trabalho no Tribunal Regional do Trabalho da $4^{\mathrm{a}}$ Região.

${ }^{2}$ Mestranda em Direitos Sociais no Programa de Pós-Graduação em Direito da Universidade Federal de Pelotas. Advogada.

${ }^{3}$ Mestranda em Direitos Sociais no Programa de Pós-Graduação em Direito da Universidade Federal de Pelotas. Advogada.
} 
Em tempos de pandemia da Covid19 e consequente isolamento social, faz-se necessário repensar diversas atividades cotidianas, como trabalhar, estudar, conviver, consumir e, de igual forma, como resolver conflitos. Independente do novo formato de vida que se estabeleceu, os conflitos continuam existindo, dentre eles os conflitos trabalhistas, os quais demandam pronta atuação em razão da natureza alimentar do crédito discutido.

Os métodos adequados de solução dos conflitos têm aplicabilidade crescente na Justiça do Trabalho, especialmente após a inauguração da política pública de tratamento dos conflitos criada pela Resolução 125 do Conselho Nacional de Justiça (BRASIL, 2010) e posterior Resolução 174 do Conselho Superior da Justiça do Trabalho (BRASIL. 2016a), com práticas preponderantes de conciliações e mediações e com a criação dos Centros Judiciários de Métodos Consensuais de Solução de Disputas (CEJUSCS).

Dessa forma, com a pandemia instalada, isolamento social e trabalho remoto, entende-se pertinente estudar de que forma os conflitos estão sendo solucionados durante o estado de calamidade que assola o País, o que justifica o presente estudo como forma de estimular o consenso e a pacificação social. Diante do cenário por ora construído, questiona-se de que forma os métodos adequados de tratamento e resolução dos conflitos estão sendo utilizados durante a pandemia como forma de acesso à justiça.

A partir de tal questionamento, o presente artigo tem como propósito analisar a adoção do sistema multiportas de resolução de conflitos no âmbito da Justiça do Trabalho, no período de isolamento social. Para tanto, serão analisados os principais métodos adequados de solução de litígios adotados na Justiça do Trabalho, como a conciliação, mediação, negociação e a homologação de acordo extrajudicial, bem como de que forma as ferramentas tecnológicas contribuem para a efetividade de tais medidas e podem ser consideradas também uma porta de acesso à justiça.

Para contemplar os objetivos apresentados, o presente trabalho tem como base o método de abordagem dedutivo, com a utilização das técnicas de pesquisa documental e bibliográfica. A pesquisa bibliográfica priorizou artigos científicos atuais, identificados com a palavras-chave que identificam este estudo, pesquisados na base de dados Web of Science, Plataforma Capes e Google Scholar, além de livros clássicos na temática. A pesquisa documental, por sua vez, pautou-se em pesquisas apresentadas pelo Conselho Nacional de Justiça (Justiça Pesquisa e Justiça em Números) e pelo Global Access to Justice Project (impactos da Covid19).

\section{O SISTEMA MULTIPORTAS COMO FORMA DE ACESSO À JUSTIÇA}

O acesso à justiça está assegurado na Constituição Federal (BRASIL, 1988) e consiste na possibilidade de acesso/ingresso no Poder Judiciário, ou seja, tem-se a garantia de que a lei não excluirá da apreciação do Poder Judiciário lesão ou ameaça de direito (art. $5^{\circ}, \mathrm{XXXV)}$.

Tradicionalmente o acesso à justiça no cenário nacional contempla a resolução consensual dos conflitos ou a solução por adjudicação (decisão por sentença, acórdão). As soluções não adjudicadas compõem o conceito de sistema multiportas de solução de 
litígios, também conhecido como Tribunal Multiportas, que consiste em analisar a possibilidade de resolução de cada conflito por uma das portas/soluções viáveis, seja a conciliação, a mediação, a arbitragem ou a própria decisão judicial. O conceito de Tribunal Multiportas foi criado pelo Professor de Harvard Law School, Frank Sander, em 1976, quando lançou um documento chamado Varieties of Disputes Processing (ALMEIDA; ALMEIDA; CRESPO, 2012).

Igualmente no intuito de debater o problema de acesso à justiça, em 1979 Mauro Cappelletti e Bryan Garth apresentam o Projeto Florença que trata sobre as restrições e soluções de acesso à justiça. Nesse sentido, afirmam os autores que "os juristas precisam, agora, reconhecer que as técnicas processuais servem a funções sociais; que as cortes não são a única forma de solução dos conflitos a ser considerada (...) precisam utilizar os métodos de análise da sociologia, da política, da psicologia, da economia" (1988, p. 1213).

Desde esses primeiros estudos referidos sobre novas modalidades de acesso à justiça, a qual começa a ser compreendida como uma solução justa e não apenas como ingresso no Poder Judiciário, a forma de tratamento dos conflitos vem passando por constante mutação e adequação, atualizando o conceito de acesso à justiça. Nesse sentido, Boaventura de Souza Santos (2011) entende que o acesso à justiça deve ser efetivado materialmente, acrescentando, ainda, que uma nova concepção de acesso à justiça passa por uma mudança cultural e de ensino do Direito.

No Brasil o sistema multiportas foi inaugurado com a Resolução 125 do Conselho Nacional de Justiça (BRASIL, 2010), a qual institui uma política judiciária nacional de tratamento adequado dos conflitos de interesses no âmbito do Poder Judiciário, com objetivo de assegurar a todos o direito à solução dos conflitos por meios adequados à sua natureza e peculiaridade. Trata-se de uma política pública de tratamento adequado dos conflitos que institui os Núcleos Permanentes de Métodos Consensuais de Solução de Conflitos (NUPEMEC) e os Centros Judiciários de Solução de Conflitos (CEJUSC) para implementar e aperfeiçoar ações voltadas ao cumprimento da política conciliatória.

No âmbito da Justiça do Trabalho, tal política pública está regulamentada pela Resolução 174 do Conselho Superior da Justiça do Trabalho (BRASIL, 2016), a qual dispõe sobre a política judiciária nacional de tratamento adequado das disputas de interesse no âmbito do Poder Judiciário Trabalhistas.

A partir da Resolução 125 do CNJ (BRASIL, 2010) deu-se início ao microssistema legal de resolução de disputas, o qual teve prosseguimento com o advento do novo Código de Processo Civil, Lei 13.105 (BRASIL, 2015a), e com a Lei 13.140 (BRASIL, 2015b), a Lei da Mediação.

Com o avanço da pesquisa sobre o acesso à justiça e o avanço normativo ora referido, é possível repensar o modelo de Justiça que até então só oferecia a solução adjudicada e passamos para um formato em que estão disponíveis às partes vários métodos e formas para resolver disputas, cada qual usando técnicas apropriadas de acordo com a demanda e a peculiaridade do caso concreto (CABRAL, 2018). 
O modelo de Sistema Multiportas mostra-se adequado na medida em que oferece uma porta/forma de resolução de acordo com a particularidade de cada conflito. Esse modelo mostra-se ainda mais importante em época de pandemia e isolamento social, em que a realidade de cada disputa difere muito e oferecer diferentes formas de solução, inclusive pela via tecnológica, é efetivar o acesso à justiça.

Nesse intuito, observada a importância dos métodos autocompositivos, o Supremo Tribunal Federal criou os Centros de Mediação e Conciliação (CMC), por meio da Resolução 697 (BRASIL, 2020e), a qual visa a solução consensual em processos que tramitam no âmbito do STF, bem como evitar a judicialização de casos que podem ser resolvidos de forma dialogada.

O conflito é inerente às relações humanas e sociais, sempre existirá na vida em sociedade, em maior ou menor grau, a depender de diversos fatores que o motivam. $\mathrm{O}$ Relatório Justiça em Números do CNJ (BRASIL, 2019) demonstra que no ano de 2018 havia cerca de 78,7 milhões de ações judiciais em andamento, o que demonstra a terceirização do conflito ao sistema de justiça. Em tempos de pandemia, de grande incerteza no cenário econômico, com reflexo direto no mercado de trabalho, muitos conflitos surgem e necessitam de respostas efetivas.

Durante o estado de calamidade pública instalado em nosso País, foram editados diversos normativos para tentar contornar e regulamentar situações até então não enfrentadas, especialmente na seara do direito do trabalho, foram editadas, por exemplo, as Medidas Provisórias 927 e 936 (BRASIL, 2020 c, d) que tratam sobre as possibilidades de manutenção e suspensão dos contratos de trabalho, disciplinando temas como o teletrabalho, banco de horas, antecipações de férias e feriados, dentre outros temas que afetam diretamente as relações de emprego.

Diante de tantas novidades fáticas e normativas, os conflitos precisam de uma resposta eficaz, tendo em vista especialmente a natureza do direito postulado, que se trata de crédito de natureza alimentar. Dessa forma, as soluções consensuais, mostram-se, mais uma vez, uma forma adequada de tratar os conflitos, não apenas pela sua celeridade, mas igualmente pela sua potencialidade em contemplar diferentes interesses, contribuindo para solução integral dos litígios e pacificação social.

\section{MÉTODOS ADEQUADOS DE SOLUÇÃO DOS CONFLITOS}

Os métodos adequados ou alternativos de resolução de disputas são uma opção que as partes em litígio dispõe para resolver seu conflito de forma mais célere e igualmente efetiva. Dessa forma, os métodos podem ser autocompositivos, quando as partes, de forma voluntária e autônoma, fazem concessões recíprocas, ainda que facilitadas por um terceiro, e chegam a uma composição, como os casos de negociação, mediação e conciliação. Os métodos heterocompositivos, ao contrário, pressupõe a solução imposta por um terceiro, como nos casos de arbitragem e a própria decisão judicial. 
A adoção dos métodos adequados na seara trabalhista encontra, ainda, alguma resistência por profissionais da área jurídica que acreditam que a solução mais justa deve ser proferida por um magistrado do trabalho. Contudo, entende-se equivocada tal premissa, tendo em vista que os métodos adequados podem conjugar o binômio celeridade e efetividade. Além disso, definir o que seria uma decisão justa e em que medida o acesso à justiça estaria ou não assegurado é tarefa difícil, dado seu caráter subjetivo.

Nesse sentido, o acesso à justiça pode ser compreendido por diferentes concepções. Pode ser entendido como o acesso formal ao Poder Judiciário, no sentido de ingressar com uma ação judicial, bem como representar o acesso material da resolução do conflito, ou seja, o resultado oferecido pelo Poder Judiciário e, ainda, pode ser entendido como o acesso efetivo à justiça enquanto manifestação da cidadania, com a tutela do seu direito (TEIXEIRA, 2018).

O conceito de desenho de sistema de disputas ou design de disputas (Dispute System Design), segundo o qual deverá haver uma análise de gestão para cada conflito, visando a solução mais eficaz, permite a compreensão de que não há uma solução pronta ou uma única porta para o acesso à justiça. $\mathrm{O}$ desenho de sistema de disputas pressupõe uma customização para atender às necessidades únicas de cada caso com maior grau de eficiência e economia, não só de tempo e recursos, mas também uma economia emocional, permitindo maior participação das partes interessadas, na busca conjunta de seus objetivos (FALECK, 2019). A depender das peculiaridades de cada caso concreto, um formato de solução será o mais adequado, seja a mediação, a arbitragem, o dispute board ou mesmo a decisão judicial, ou seja, cada litígio terá uma decisão/porta que garanta o acesso mais efetivo à justiça.

Diante de inúmeros métodos e estratégias para resolução de conflitos, este trabalho destina-se ao estudo da conciliação, da mediação, da negociação, da arbitragem e da homologação de acordo extrajudicial, tendo em vista a limitação à seara laboral.

\subsection{Conciliação}

No âmbito da Justiça do Trabalho a conciliação é o meio adequado de resolução de disputas em que as partes confiam a uma terceira pessoa, a função de aproximá-las, empoderá-las e orientá-las na construção de um acordo quando a lide já está instaurada, com a criação ou proposta de opções para composição do litígio, conforme redação dada pelo art. $1^{\circ}$ da Resolução 174 do CSJT (BRASIL, 2016a).

No processo trabalhista a conciliação judicial é uma prática já adotada, por determinação da própria Consolidação das Leis do Trabalho, artigos 764, 846 e 850 (BRASIL, 1943). A Justiça do Trabalho é pautada no espírito conciliador, do estabelecimento do diálogo entre as partes em todas as fases processuais, sendo destacada dentre os demais ramos do Poder Judiciário como o ramo mais conciliador. $\mathrm{O}$ destaque na solução conciliatória pode ser percebido no relatório Justiça em Números do Conselho Nacional de Justiça do ano de 2019 (ano base 2018), o qual informa que na fase de conhecimento o índice de conciliação da Justiça do Trabalho foi de $39 \%$, enquanto que na Justiça Federal foi de $11 \%$ e na Justiça Estadual $18 \%$. 
A conciliação ocorre preponderantemente em âmbito processual, ou seja, no ambiente judicial, sendo desenvolvida por servidor conciliador supervisionado por um magistrado ou o próprio magistrado pode conduzir as audiências de conciliação.

O processo laboral está constantemente sujeito à conciliação, na qual as partes interessadas, avaliam as circunstâncias fáticas do processo, seu ônus de prova e o contexto probatório porventura existente e, com base nessas premissas, negociam entre si, estabelecendo mútuas concessões para contemplar o acordo. Dessa forma, a conciliação ocorre de forma mais linear, ou seja, está voltada às circunstâncias debatidas no processo e não necessariamente no relacionamento existente entre as partes (GABBAY, 2013).

No avançar das tratativas conciliatórias, o juiz do trabalho atua atento à assimetria das partes, peculiar nas relações laborais, identificando todos os requisitos para que o acordo contemple a vontade das partes e preencha os requisitos legais, de forma que o juiz não exerce uma atividade cartorária, mas verifica em profundida a existência dos requisitos do ato jurídico, a manifestação de vontade das partes livre e sem vício e, ainda, a pertinência do conteúdo acordado (CALMON, 2015). Nesse sentido, ao fazer a verificação de validade e adequação do acordo ora celebrado, o juiz do trabalho não está obrigado a homologar a transação proposta, não havendo direito líquido e certo das partes à homologação, sendo incabível a impetração de mandado de segurança para obter a homologação compulsória, conforme Súmula 418 do Tribunal Superior do Trabalho (BRASIL, 2017b).

Em tempos de pandeia, em que a regularidade da tramitação processual não está normalizada, especialmente no tocante ao prosseguimento das audiências de instrução, o que obsta em parte o andamento processual, mostra-se oportuna a aproximação das partes interessadas para estabelecer um diálogo sobre processos em curso, para que aproximando seus interesses e fazendo mútuas concessões possam estabelecer uma solução conciliada ao litígio.

Nesses casos, os magistrados do trabalho podem, uma vez verificada a regularidade e adequação do acordo apresentado, homologar em secretaria ou designar audiência conciliatória por videoconferência para esclarecer algum ponto obscuro do acordo. As partes podem, ainda, peticionar em seus processos e solicitar a designação de audiência por vídeo para tentativa de acordo, caso entendam que a intervenção do magistrado ou do conciliador como facilitadores pode propiciar a solução consensual.

\subsection{Mediação}

De acordo com a disciplina da Resolução 174 do CSJT (BRASIL, 2016a), a mediação é o meio adequado de resolução de disputas em que as partes confiam a uma terceira pessoa, a função de aproximá-las, empoderá-las e orientá-las na construção de um acordo quando a lide já está instaurada, sem a criação ou proposta de opções para composição do litígio.

Uma das principais finalidades da mediação é restaurar a relação entre as partes, as quais identificam de forma autônoma a solução mais adequada ao seu conflito e, por 
consequência, restabelecem a relação até então mantida. Não apenas o problema jurídico é resolvido, mas também a lide sociológica. $\mathrm{O}$ mediador atua como um facilitador apenas, propiciando que as próprias partes reflitam e identifiquem a construção conjunta da solução do litígio.

A mediação consiste em uma atividade destinada a fazer com que as partes encontrem pacificamente uma solução para o conflito de interesses entre elas, em que as partes são responsáveis por essa solução, com criação de regras próprias e com a facilitação do mediador, o qual controla a conversa e auxilia as partes a identificarem seus pontos de interseção e interesses para construção do acordo e manutenção do relacionamento (TARGA, 2004).

A mediação difere da conciliação essencialmente no proceder do terceiro facilitador, uma vez que o conciliador pode emitir a sua opinião e sugestão de proposta para a solução do conflito, o mediador atua com base em método estruturado em etapas sequenciais, atuando como um condutor apenas, dirigindo as partes, mas sem emitir qualquer opinião ou conselho (CALMON, 2015).

É necessária a quebra de paradigma no curso da mediação, possibilitando que as partes identifiquem nas diferenças os interesses em comum, percebendo o conflito como algo natural e inevitável da vida em sociedade, o que não impede que as diferenças sejam reconhecidas e seja possível trilhar novos caminhos com a administração adequada das controvérsias (NUNES; BAHIA; PEDRON, 2020).

O procedimento da mediação é voluntário e confidencial, com método próprio, informal e coordenado, observados especialmente os princípios da neutralidade e da confidencialidade. De acordo com Calmon (2015), como são as partes que constroem a solução de forma colaborativa e conjunta, a mediação pressupõe uma negociação, ou seja, não há mediação sem que as partes tenham passado previamente pela etapa de negociação.

Importante destacar que a mediação no âmbito da Justiça do Trabalho não é regulada pela Lei de Mediação, Lei 13.140 (BRASIL, 2015b), por expressa previsão do art. 42, o qual prevê que a mediação nas relações de trabalho será regulada por lei própria, com aplicação da Consolidação das Leis do Trabalho (BRASIL, 1943) e da própria Resolução 174 do CSJT (BRASIL, 2016a).

Durante o período de pandemia faz-se oportuna a adoção dos métodos adequados para resolução de controvérsias, considerando especialmente que o momento de calamidade propicia o surgimento de inúmeros litígios decorrentes da vida em sociedade e, da mesma forma, os litígios trabalhistas em razão de extinções contratuais, suspensões e diversas controvérsias que surgem da crise instalada.

Nesse contexto, o Conselho Superior da Justiça do Trabalho editou a Resolução 01 (BRASIL, 2020b), a qual ressalta a importância da mediação e da conciliação para resolução de controvérsias no período de pandemia de Covid19 e assegura a possibilidade da mediação pré-processual em dissídios individuais, especialmente para conflitos individuais que digam respeito a interesses do exercício de atividades laborativas e funcionamento das atividades empresariais no contexto da situação extraordinária da pandemia. Até então a mediação pré-processual na seara trabalhista estava limitada aos 
dissídios coletivos, conforme previsto no Ato 168 TST.GT (BRASIL, 2016b), o qual servirá de amparo normativo, além do art. $3^{\circ}$ do Código de Processo Civil (BRASIL, 2015a) e do art. 611-A da Consolidação das Leis do Trabalho (BRASIL, 1943), no que couber, às mediações pré-processuais individuais.

A previsão das mediações pré-processuais individuais, por ora, está limitada ao período da pandemia. Nesse cenário, importante atentar à inércia e à imparcialidade do magistrado, sendo adequado que o juiz que supervisiona as mediações pré-processuais não seja o mesmo que, no insucesso, irá julgar o processo. Uma medida adequada seria estabelecer a competência exclusiva dos CEJUSC-JT para as mediações pré-processuais, caso em que os princípios da imparcialidade e da confidencialidade restariam preservados.

\subsection{Arbitragem}

A arbitragem está prevista na Lei 9.307 (BRASIL, 1996) com a finalidade de solucionar conflitos sobre direitos patrimoniais disponíveis entre pessoas capazes. Destacase que a arbitragem é um instituto há tempos previsto no ordenamento jurídico, tinha previsão já no Código Comercial de 1850, referindo a solução dos conflitos feita por árbitros.

A atual legislação apresenta alguns requisitos para submissão de um litígio à arbitragem: direitos patrimoniais disponíveis e pessoas capazes. Com esses requisitos a arbitragem sempre teve sua função muito limitada na seara do direito laboral, especialmente em relação aos direitos individuais, os quais são imperativos e de ordem pública. Contudo, no âmbito do direito coletivo, a arbitragem tem maior aplicabilidade, como prevê o art. 114, parágrafos $1^{\circ}$ e $2^{\circ}$ da Constituição Federal (BRASIL, 1988).

O autor Gustavo Filipe Barbosa Garcia (2016) faz uma crítica a extensão da indisponibilidade dos direitos trabalhistas, eis que se fossem totalmente indisponíveis, não poderia ser reconhecida a confissão ficta, a exemplo do previsto na Súmula 74 do Tribunal Superior do Trabalho (BRASIL, 2016c), diante do teor do art. 345, II e art. 392 do CPC (BRASIL, 2015a).

A legislação brasileira adotou o modelo da arbitragem voluntária, a qual, necessariamente, decorre da vontade das partes por meio da celebração de um compromisso arbitral ou de uma cláusula compromissória. O compromisso arbitral consiste num acordo entre os envolvidos, no qual optam por submeter um conflito já existente a uma decisão arbitral. Já a cláusula compromissória precede o conflito, em que as partes ajustam que, na existência de uma controvérsia futura, submetem-se desde logo à arbitragem.

Especificamente na seara laboral, a Lei 13.467 (BRASIL, 2017a) introduziu o art. 507-A na CLT (BRASIL, 1943), o qual prevê que nos contratos individuais de trabalho

\footnotetext{
4 art. 345, II (a revelia não produz o efeito mencionado no art. 344 se: II - o litígio versar sobre direitos indisponíveis) e art. 392 (não vale como confissão a admissão, em juízo, de fatos relativos a direitos indisponíveis), $\mathrm{CPC} / 2015$.
} 
cuja remuneração seja superior a duas vezes o limite máximo estabelecido para os benefícios do Regime Geral de Previdência Social, poderá ser pactuada cláusula compromissória de arbitragem, desde que por iniciativa do empregado ou mediante a sua concordância expressa, nos termos previstos na Lei de Arbitragem.

A redação do artigo traz dois requisitos para opção da arbitragem nos contratos individuais de trabalho: o valor do salário do empregado e que essa opção ocorra mediante a celebração de uma cláusula compromissória, ou seja, que as partes pactuem antes da existência do conflito, não sendo possível a celebração de compromisso arbitral para os contratos individuais de trabalho extintos.

A cláusula compromissória referida no art. 507-A da CLT (BRASIL, 1943) deverá ser celebrada por iniciativa do empregado ou com sua expressa concordância, em razão da sua natureza substitutiva da jurisdição estatal. Nesse ponto cabe a reflexão sobre a vulnerabilidade do empregado. Para relativizar tal condição, o legislador exigiu a remuneração do empregado seja superior a duas vezes o limite máximo estabelecido para os benefícios do Regime Geral de Previdência Social. Contudo, o valor da remuneração não é o indicativo mais legítimo para verificar a condição de vulnerável ou não do empregado em determinada relação. Note-se que o legislador, no art. 444, parágrafo único da CLT (BRASIL, 1943), também com redação dada pela Reforma Trabalhista, foi mais rígido ao prever a livre estipulação contratual entre as partes, pois aponta como requisitos que o empregado seja portador de diploma de nível superior e que perceba salário mensal igual ou superior a duas vezes o limite máximo dos benefícios do Regime Geral de Previdência Social.

A partir da leitura do art. 507-A da CLT (BRASIL, 1943) pode-se questionar a sua constitucionalidade, pois limitaria o acesso à justiça, ferindo o princípio da inafastabilidade do Poder Judiciário, previsto no art. 5 XXXV da Constituição Federal (BRASIL, 1988). Contudo, o Supremo Tribunal Federal já se pronunciou sobre a constitucionalidade da lei arbitral (SE 5206), afirmando também que o direito de acesso à justiça comporta exceções, como ocorre no direito desportivo, ressalvada a possibilidade de apreciação pelo Poder Judiciário sobre aspectos formais e de consentimento. A interpretação do STF é no sentido da constitucionalidade da arbitragem voluntariamente acordada pelos interessados, violando a Constituição Federal somente a previsão da arbitragem compulsória.

O legislador utilizou como critério de validade para celebração da cláusula compromissória o valor do salário do empregado, o que, por si só, pode não representar a manifestação hígida de sua vontade, tendo em vista a natureza de contrato de adesão peculiar aos contratos de trabalho. Contudo, a cláusula compromissória não será um obstáculo de acesso ao Poder Judiciário no âmbito do contrato individual do trabalho, uma vez que, por se tratar de espécie de contrato de adesão, a instituição da arbitragem deve ser de iniciativa do empregado aderente ou ter a sua expressa concordância, nos termos do art. $4^{\circ}, \S 2^{\circ}$ da Lei de Arbitragem. Dessa forma, ainda que a cláusula compromissória esteja prevista no contrato de trabalho, não bastará a provocação do empregador para instituição da arbitragem, caso o empregado não concorde com essa via para solução do litígio.

\subsection{Negociação}


A negociação é muito mais do que um método de resolver problemas, é um processo que está presente de forma contínua em todos os demais formatos de solução de litígios, seja na mediação, na conciliação, na arbitragem.

Ao praticar a negociação, os advogados e partes interessadas utilizam a arte de persuadir, demonstrar seu ponto de vista e, também, devem saber escutar para compreender as razões da parte contrária. Nesse sentido, a negociação pode apresentar o formato colaborativo, o qual evita ao máximo o conflito e visa manter a relação entre as partes, o formato competitivo, com a intenção da disputa e de obter o máximo de benefícios possível, ainda que esse resultado custe a perda da relação entre os negociadores e, por fim, o formato da negociação baseada em princípios, modelo de negociação de Harvard, que visa preservar e conjugar os interesses de ambas as partes, resultando em mútuos benefícios (FISHER; URY; PATTON, 2015).

O Código de Processo Civil (BRASIL, 2015a), em seu art. 381, disponibiliza importante instrumento a serviço da negociação, qual seja a Produção Antecipada de Provas (PAP), com intuito de subsidiar as partes com concretas informações sobre o contrato de trabalho para que possam negociar. O inciso III do referido artigo dispõe que uma das finalidades do PAP é que o prévio conhecimento dos fatos possa justificar ou evitar o ajuizamento de ação É um estímulo à desjudicialização, pois as partes podem conhecer documentalmente a realidade do contrato de trabalho e, dessa forma, avaliar o melhor caminho e fazer um acordo extrajudicial.

A negociação é uma etapa prévia dos demais métodos adequados de solução dos conflitos, uma vez que possibilita a escuta e o diálogo, propiciando a resolução dos litígios de forma consensual e pacífica. Em tempos de pandemia e distanciamento social, a negociação constitui uma ferramenta essencial na gestão de conflitos, considerando, especialmente, a potencialidade do surgimento de conflitos até então desconhecidos e que, por essa razão, justificam uma solução dialogada e que comporte a adequação de diferentes interesses.

\subsection{Homologação de Acordo Extrajudicial}

O procedimento de jurisdição voluntária para homologação de acordo extrajudicial foi introduzido na norma celetista pela Lei 13.467 (BRASIL, 2017a) e trata-se de importante instrumento na solução adequada de conflitos trabalhistas, uma vez que pressupõe o diálogo prévio dos interessados.

A homologação do acordo extrajudicial constitui uma forma autocompositiva de solução dos litígios, está prevista no art. 855-B e seguintes da CLT (BRASIL, 1943) e decorre da negociação extrajudicial das partes interessadas, as quais submetem seu acordo e suas condições para homologação pelo Poder Judiciário.

O legislador reformista foi tímido em suas previsões sobre o novo instituto, de forma que a disciplina da matéria na norma celetista apresenta requisitos de admissibilidade e de procedimento de forma rasa. Constitui requisito essencial que as partes estejam representadas por advogados distintos, facultando-se ao empregado fazer-se 
representar pelo sindicato de sua categoria. Tal requisito constitui uma exceção ao jus postulandi em grau ordinário, conforme previsão no art. 791 da CLT (BRASIL, 1943). Essa previsão visa impedir, ou pelo menos reduzir, a incidência de fraudes no âmbito processual trabalhista, eis que no acordo firmado por advogados distintos, pressupõe-se que foi precedido de diálogo e concessões mútuas entre os interessados (ARENA, 2019).

Ao magistrado trabalhista cabe a condução do procedimento da forma como entender mais adequada para avaliar se os termos do acordo proposto podem ou não ser homologados, se preenchidos seus requisitos mínimos e assegurados os direitos fundamentais trabalhistas do empregado. Para tanto, poderá designar audiência para oitiva dos interessados, propor adequação de cláusulas do acordo, bem como de limitação da extensão da quitação, que pode ser restrita ao objeto do acordo ou alcançar o contrato de trabalho integralmente.

Por se tratar de um procedimento de jurisdição voluntária, não há lugar para a vontade substitutiva estatal. Em caso de discordância com algum ponto dúbio do acordo, o magistrado deve "preferir o aprimoramento da composição, reconstruindo-o consensualmente com as partes, para, sempre que possível, aproveitar os atos já realizados e a disponibilidade dos envolvidos para a prevenção ou solução do conflito" (BARBOSA, 2020, p. 88), o que se denomina de princípio da primazia do mérito integrativo.

$\mathrm{O}$ intuito do procedimento de homologação de acordo extrajudicial é de que as partes negociem diretamente suas pretensões e, após chegarem a um consenso, apresentem à Justiça do Trabalho, os termos do acordo para homologação, o qual, se homologado, formará coisa julgada.

\section{A VIA TECNOLÓGICA: ONLINE DISPUTE RESOLUTION}

As mudanças proporcionadas pela Revolução 4.0 já podem ser percebidas na vida em sociedade, na forma como trabalhamos, nos relacionamos, nos monitoramos (SCHAWB, 2016) e estão pautadas em inovações digitais, automação, adoção de inteligência artificial, algoritmo, big data.

Direito e tecnologia estão atuando de forma cada vez mais conjunta no cenário mundial e no Brasil já temos iniciativas digitais no Poder Judiciário, a exemplo do Processo Judicial Eletrônico, as quais foram impulsionadas com o estado de calamidade, decorrente da pandemia de Covid19. Isso porque o avanço da pandemia não pode consistir em barreira para o acesso à justiça e materialização de direitos (SOUZA NETTO; FOGAÇA; GARCEL, 2020).

O trabalho remoto desafia soluções tecnológicas e, no âmbito de resoluções de disputas, já há a adoção da prática da Online Dispute Resolution (ODR) em âmbito extrajudicial com sucesso e satisfação dos usuários, conforme é possível perceber com a publicação de trabalhos científicos sobre a atuação extrajudicial (MARQUES, 2019). Contudo, a seara judicial ainda desafia estudos sobre a sua compatibilidade com a ODR.

Percebe-se que a virtualização do conflito, com digitalização dos dados que envolvem a sua solução adequada, permite a formação de um banco de dados (big data) 
estruturado e analisado de acordo com uma classificação, o qual pode contribuir para a prevenção de litígios futuros, uma vez que será oportunizado aos interessados o conhecimento desses resultados (Exemplos Ebay e Mercado Livre). As próprias relações digitais requerem soluções igualmente digitais e essa modificação passa também pela interpretação do acesso à justiça.

Pode-se constatar, ainda, que a ODR, como uma forma de solução adequada de conflitos, possui características positivas como proporcionar acesso à justiça, prevenir litígios judiciais, permitir a formulação de um adequado design de sistema de disputa, eliminar barreiras físicas e gerar economia financeira (MARQUES, 2019).

A via tecnológica como forma de solução de conflitos também apresenta limitações, como a falta de regulamentação normativa e a desigualdade social e tecnológica no Brasil (letramento digital), que não permite que toda sociedade tenha acesso à internet (SOUZA NETTO; FOGAÇA; GARCEL, 2020).

Diante de novas demandas sociais (digitais), deve-se atentar para as novas perspectivas e necessidades do acesso à justiça no Brasil, propor uma nova agenda de pesquisa e atuação, de acordo com os tempos atuais, e não somente repetir de forma acrítica as ondas renovatórias de Cappelletti e Garth (GABAY; COSTA; ASPERTI, 2019). Nesse sentido, mostra-se necessária a atenção também para o acesso tecnológico à justiça (ORSINI; LEME, 2017), de acordo com a nova realidade social imposta pela Revolução 4.0 .

Por constituir a ODR uma modalidade do Sistema Multiportas de Acesso à Justiça, é adequado e necessário o aprofundamento de seu estudo para implementação de forma mais abrangente do âmbito do Poder Judiciário. Isso porque, diante de um mundo globalizado, com relações cada mais virtuais e assíncronas (FERRARI, 2020), o sistema de justiça deve acompanhar a evolução da sociedade.

Em tempos de pandemia de Covid19, a solução tecnológica foi a única alternativa para a continuidade das atividades do Poder Judiciário, antecipando ainda mais a discussão sobre a necessidade da tecnologia no sistema de justiça. Foram editados normativos prevendo a manutenção das atividades por meio remoto e digital, a exemplo da Resolução 313 do Conselho Nacional de Justiça (BRASIL, 2020a) e diversas outras regulamentações editadas no âmbito do CNJ e dos Tribunais de todo País, disciplinando a adoção da via tecnológica para prestação de serviço jurisdicional.

Dados do relatório impactos da Covid19 do Global Access to Justice Project (2020) atestam que pelo menos $78 \%$ dos Tribunais adotaram medidas especiais de atuação no período da pandemia e que 53\% dos Tribunais estão realizando audiências por videoconferência. Ainda, segundo dados estatísticos do $\mathrm{CNJ}^{5}$, já foram realizadas mais de 533 mil audiências por videoconferência durante o período de isolamento social.

${ }^{5}$ Consulta disponível em: https://paineisanalytics.cnj.jus.br/single/?appid=a89ef492-f81e-4679-a58ff7caa 7452d82\&sheet=740707b2-b87f-4ac0-a185-b430f855e682\&lang=pt-BR\&opt=currsel\&select=clearall. Acesso em 12/09/2020. 
De acordo com esses dados, e considerando especialmente o período de pandemia, é possível constatar que as novas tecnologias, aliadas às soluções adequadas dos conflitos, podem resultar em acesso à justiça e efetividade de direitos fundamentais também no âmbito judicial.

\section{CONCLUSÃO}

O direito de acesso à justiça não deve se resumir em direito de ingressar no Poder Judiciário, mas sim ao direito de acesso ao mecanismo mais efetivo para resolver seu litígio. Dessa forma, o Sistema Multiportas de Solução de Conflitos deve ser estimulado e propagado, pois representa efetivo acesso à justiça, de forma customizada (não massificada), considerando a peculiaridade de cada litígio e qual a melhor solução para aquela demanda particular, ou seja, qual a porta de acesso que irá propiciar a solução mais adequada.

Diante das incertezas causadas pela pandemia de Covid19, particularmente em relação ao mercado econômico e de trabalho, a solução consensual dos conflitos mostra-se extremamente relevante e adequada, pois permite que as partes sejam protagonistas da resolução dos seus problemas. As soluções consensuais firmadas no âmbito da Justiça do Trabalho são pautadas em preceitos éticos e com a decisão informada às partes, sempre com intuito de garantir efetividade aos direitos fundamentais trabalhistas.

Nesse sentido, a tecnologia pode ser uma aliada para prevenir, tratar e resolver conflitos, inclusive no âmbito judicial. Especialmente em tempos de pandemia de Covid19 e distanciamento social, a via tecnológica mostra-se mais uma porta de acesso à justiça, consentânea com a demanda atual da sociedade digital.

Destaca-se, ainda, que a via tecnológica de acesso à justiça, com implementação da ODR em âmbito judicial, vai ao encontro da sexta onda de acesso à justiça (Global Access to Justice Project), a qual prevê que as novas tecnologias devem aprimorar o acesso à justiça.

Um desafio teórico é a continuidade do estudo das formas adequadas de solução dos conflitos aliadas à via tecnológica, com a efetiva implementação da ODR no âmbito do Poder Judiciário, a melhor forma de operacionalização, considerada as peculiaridades de cada ramo judicial.

Por fim, destaca-se que a contribuição científica da presente pesquisa consiste na possibilidade de adoção dos métodos adequados de solução dos conflitos, inclusive pela via tecnológica, como forma de acesso à justiça, especialmente no período de isolamento social em razão da pandemia de Covid19. A contribuição social, por sua vez, consiste na propagação dos referidos métodos adequados como forma de resolução integral do conflito, contribuindo para a efetividade de direitos fundamentais e para a pacificação social.

\section{REFERÊNCIAS}

Revista Cidadania e Acesso à Justiça | e-ISSN: 2526-026X | Encontro Virtual | v. 6 | n. 2 | p. 01 17 | Jul/Dez. 2020. 
ALMEIDA, R. A. DE; ALMEIDA, T.; CRESPO, M. H. Tribunal Multiportas. Rio de Janeiro: FGV, 2012.

ARENA, Marcela Casanova Viana. Homologação de Acordo Extrajudicial na Justiça do Trabalho: análise prática do seu procedimento e requisitos. Revista da Escola Judicial do TRT4, Porto Alegre, v.1, n.2, p. 141-158, 2019.

BARBOSA, Amanda. Acordo Extrajudicial Trabalhista: Ação para Homologação e o Princípio da Primazia do Mérito Integrativo. Transação Extrajudicial, v. Ano IX, n., p. 74-92, 2020.

BRASIL. [Constituição (1988)]. Constituição da República Federativa do Brasil de 1988. Brasília: Presidência da República, [2020]. Disponível em: http://www.planalto.gov.br/ccivil_03/constituicao/constituicao.htm. Acesso em 09 set. 2020.

BRASIL. Conselho Nacional de Justiça. Relatório Justiça em números 2019, ano-base 2018. Brasília, DF: Conselho Nacional de Justiça, 2019. Disponível em: http://www.cnj.jus.br/files/conteudo/arquivo/2018/08/44b7368ec6f888b383f6c3de40c3216 7.pdf. Acesso em 30 ago. 2020

BRASIL. Conselho Nacional de Justiça. Resolução 125, de 29 de novembro de 2010. Dispõe sobre a Política Judiciária Nacional de tratamento adequado dos conflitos de interesses no âmbito do Poder Judiciário e dá outras providências. Brasília, DF: Conselho Nacional de Justiça, [2016]. Disponível em: https://www.cnj.jus.br/busca-atosadm?documento $=2579$.

BRASIL. Conselho Nacional de Justiça. Resolução 313, de 19 de março de 2020a. Estabelece, no âmbito do Poder Judiciário, regime de Plantão Extraordinário, para uniformizar o funcionamento dos serviços judiciários, com o objetivo de prevenir o contágio pelo novo Coronavírus - Covid-19, e garantir o acesso à justiça neste período emergencial.. Brasília, DF: Conselho Nacional de Justiça, [2020]. Disponível em https://atos.cnj.jus.br/atos/detalhar/3249.

BRASIL. Conselho Superior da Justiça do Trabalho. Resolução 174, de 30 de setembro de 2016a. Dispõe sobre a política judiciária nacional de tratamento adequado das disputas de interesses no âmbito do Poder Judiciário Trabalhista e dá outras providências. Brasília, DF: Conselho Superior da Justiça do Trabalho, 2016. Disponível em: http://www.csjt.jus.br/c/document_library/get_file?uuid=235e3400-9476-47a0-8bbb-

bccacf94fab4\&groupId=955023.

BRASIL. Conselho Superior da Justiça do Trabalho. Resolução 01, de 25 de março de 2020b. Recomenda a adoção de diretrizes excepcionais para o emprego de instrumentos de mediação e conciliação de conflitos individuais e coletivos em fase processual e fase préprocessual por meios eletrônicos e videoconferência no contexto da vigência da pandemia do Novo Coronavirus (COVID-19. Brasília, DF: Conselho Superior da Justiça do Trabalho, 2020.

Disponível

em:

https://juslaboris.tst.jus.br/handle/20.500.12178/169693\#: :text=Recomenda\%20a\%20ado $\% \mathrm{C} 3 \% \mathrm{~A} 7 \% \mathrm{C} 3 \% \mathrm{~A} 3 \mathrm{o} \% 20 \mathrm{de} \% 20$ diretrizes, Coronavirus\%20(COVID\%2D19).

BRASIL. Decreto-Lei 5452, de $1^{\circ}$ de maio de 1943. Aprova a Consolidação das Leis do Trabalho. Rio de Janeiro, RJ: Presidência da República, [2020]. Disponível em http://www.planalto.gov.br/ccivil_03/Decreto-Lei/Del5452.htm. Acesso em 15 ago. 2020.

Revista Cidadania e Acesso à Justiça | e-ISSN: 2526-026X | Encontro Virtual | v. 6 | n. 2 | p. 01 17 | Jul/Dez. 2020. 
BRASIL. Lei 9.307, de 23 de setembro de 1996. Dispõe sobre a arbitragem. Brasília, DF: Presidência da República, [1996]. Disponível em http://www.planalto.gov.br/ccivil_03/leis/19307.htm Acesso em 10 jul. 2020.

BRASIL. Lei 13.105, de 16 de março de 2015a. Código de Processo Civil. Brasília, DF: Presidência da República, [2019]. Disponível em http://www.planalto.gov.br/ccivil_03/_Ato2015-2018/2015/Lei/L13105.htm. Acesso em 22 ago. 2020.

BRASIL. Lei 13.140, de 26 de junho de 2015b. Dispõe sobre a mediação entre particulares como meio de solução de controvérsias e sobre a autocomposição de conflitos no âmbito da administração pública. Brasília, DF: Presidência da República, [2019]. Disponível em http://www.planalto.gov.br/ccivil_03/_ato2015-2018/2015/lei/113140.htm. Acesso em 10 jul. 2020.

BRASIL. Lei 13.467, de 13 de julho de 2017a. Altera a Consolidação das Leis do Trabalho (CLT), aprovada pelo Decreto-Lei $\mathrm{n}^{\mathrm{0}}$ 5.452, de $1^{\circ} \mathrm{o}$ de maio de 1943 , e as Leis $\mathrm{n}^{\mathrm{os}}$ 6.019, de 3 de janeiro de $1974,8.036$, de 11 de maio de 1990 , e 8.212 , de 24 de julho de 1991, a fim de adequar a legislação às novas relações de trabalho. Brasília: Presidência da República, [2017]. Disponível em http://www.planalto.gov.br/ccivil_03/_Ato20152018/2017/Lei/L13467.htm. Acesso em 15 ago. 2020.

BRASIL. Medida Provisória 927 de 22 de março de 2020c. Dispõe sobre as medidas trabalhistas para enfrentamento do estado de calamidade pública em razão da pandemia de Covid10. Diário Oficial da União, Brasília, DF, 22 mar.2020, edição extra.

BRASIL. Medida Provisória 936 de 01 de abril de 2020d. Institui o Programa Emergencial de Manutenção do Emprego e Renda e dispõe sobre medidas trabalhistas complementares. Diário Oficial da União, Brasília, DF, 01 abr.2020, edição extra.

BRASIL. Supremo Tribunal Federal. Resolução 697, de 06 de agosto de 2020e. Dispõe sobre a criação do Centro de Mediação e Conciliação, responsável pela busca e implementação de soluções consensuais no Supremo Tribunal Federal. [2020]. Disponível em: http://www.stf.jus.br/arquivo/cms/noticiaNoticiaStf/anexo/DJE198.pdf

BRASIL. Tribunal Superior do Trabalho. Ato n. 168/TST.GP, de 4 de abril de 2016b. Dispõe sobre os pedidos de mediação e conciliação pré-processual de conflitos coletivos no âmbito do Tribunal Superior do Trabalho. 2016b. Disponível em https://juslaboris.tst.jus.br/handle/20.500.12178/82592

BRASIL. Tribunal Superior do Trabalho. Súmula 74, I. Aplica-se a confissão à parte que, expressamente intimada com aquela cominação, não comparecer à audiência em prosseguimento, na qual deveria depor. Brasília, DF: Tribunal Superior do Trabalho, [2016c].

Disponível

em http://www3.tst.jus.br/jurisprudencia/Sumulas com indice/Sumulas Ind 51 100.html\#SU M-74. Acesso em 22 ago. 2020.

BRASIL. Tribunal Superior do Trabalho. Súmula 418. A homologação de acordo constitui faculdade do juiz, inexistindo direito líquido e certo tutelável pela via do mandado de segurança. Brasília, DF: Tribunal Superior do Trabalho, [2017b]. Disponível em http://www3.tst.jus.br/jurisprudencia/Sumulas_com_indice/Sumulas_Ind_401_450.html\#S UM-402. Acesso em 22 ago. 2020.

CABRAL, Trícia Navarro Xavier. O Modelo de Justiça Multiportas no Brasil. In: TUPINAMBA, Carolina. Soluções dos conflitos trabalhistas: novos caminhos/ Carolina Tupinambá (coordenação). - São Paulo: LTR, 2018.

Revista Cidadania e Acesso à Justiça | e-ISSN: 2526-026X | Encontro Virtual | v. 6 | n. 2 | p. 01 17 | Jul/Dez. 2020. 
CALMON, Petronio. Fundamentos da mediação e da conciliação. - 3 ed. - Brasília: Gazeta Jurídica, 2015.

CAPPELLETTI, Mauro, GARTH; Bryant. Acesso à justiça. Tradução de Ellen Gracie Northfleet. Porto Alegre: Fabris, 1998.

FALECK, Diego. Um passo adiante para resolver problemas complexos: desenho de sistemas de disputas. In: BRAGA NETO, Adolfo et. al. Negociação, Mediação, Conciliação e Arbitragem: curso de métodos adequados de solução de controvérsias. 2a ed. - Rio de Janeiro: Forense, 2019

FERRARI, Isabela. Justiça Digital - São Paulo: Thomson Reuters Brasil, 2020.

FISHER, Roger, URY, Willian, PATTON, Bruce. Como chegar ao sim: como negociar acordo sem fazer concessões. Rio de Janeiro: Sextante, 2018.

GABBAY, Daniela Monteiro. Mediação \& Judiciário no Brasil e nos EUA: condições, desafios e limites para institucionalização da mediação no Judiciário. Brasília: Gazeta Jurídica, 2013.

GABBAY, Daniela Monteiro; COSTA, Susana Henriques da; ASPERTI, Maria Cecília Araújo. Acesso à Justiça no Brasil: reflexões sobre escolhas políticas e a necessidade de construção de uma nova agenda de pesquisa. Revista Brasileira de Sociologia do Direito, São Paulo, v.6, n.3, p. 152- 181, 2019.

GARCIA, Gustavo Filipe Barbosa. Curso de Direito do Trabalho. 10. ed. Rio de Janeiro: Forense, 2016

Global Access to Justice Project. Impactos da Covid19 nos Sistemas de Justiça. Disponível em: http://globalaccesstojustice.com/impacts-of-covid-19/?lang=ptbr\#graphic10. Acesso em 28 jul. 2020.

MARQUES, Ricardo. A Resolução de Disputas Online (ODR): do comércio eletrônico ao seu efeito transformador sobre o conceito e a prática do acesso à justiça. Revista de Direito e as Novas Tecnologias, v.5, 2019.

NUNES, Dierle, BAHIA, Alexandre, PEDRON, Flávio Quinaud. Teoria Geral do Processo: comentários sobre a virada tecnológica no direito processual. - Salvador: Editora JusPodivm, 2020.

ORSINI, Adriana Goulart de Sena; LEME, Ana Carolina Reis Paes. Acesso Tecnológico à Justiça no Contexto da Sociedade em Rede: compartilhando (in) justiça. Compendi Law Review, Braga - Portugal, v.3, n.2, p. 202-218, 2017.

SANTOS, Boaventura de Souza. Para uma Revolução Democrática da Justiça. $3^{\text {a }}$ ed. São Paulo: Cortez, 2011.

SCHAWB, Klaus. A quarta revolução industrial; tradução de Daniel Moreira Miranda. São Paulo: Edipro, 2016.

SOUZA NETTO, José Laurindo; FOGAÇA, Anderson Ricardo; GARCEL, Adriane. Métodos Autocompositivos e as Novas Tecnologias em Tempos de Covid19: online dispute resolution - ODR. Revista de Relações Internacionais do Mundo Atual, Curitiba, v. 26, p. 21-32, 2020.

TARGA, Maria Inês Corrêa de Cerqueira César. Mediação em juízo. São Paulo: LTR, 2004.

TEIXEIRA, Sérgio Torres. Mitos, Caminhos e Acesso Multidimensional à Justiça: Arbitragem e Mediação como Fórmulas Parceiras do Judiciário do Trabalho no Brasil. In:

Revista Cidadania e Acesso à Justiça | e-ISSN: 2526-026X | Encontro Virtual | v. 6 | n. 2 | p. 01 17 | Jul/Dez. 2020. 
TUPINAMBA, Carolina. Soluções dos conflitos trabalhistas: novos caminhos/ Carolina Tupinambá (coordenação). - São Paulo: LTR, 2018. 